Impacto de las reformas sobre el ausentismo laboral en los hospitales de Costa Rica

El ausentismo laboral, la información deficiente, el remoloneo, el doble empleo y la aceptación de pagos indebidos constituyen males ampliamente difundidos entre los médicos y el personal sanitario de los servicios públicos de salud en los países en desarrollo. Sin embargo, a pesar de las graves consecuencias que estos problemas acarrean, no han sido objeto de suficiente discusión por parte de las autoridades de salud de esos países.

En Costa Rica, el ausentismo injustificado o inexplicado de los médicos y enfermeros es elevado. En este trabajo se analiza si después de la aplicación de las nuevas normas organizativas adoptadas por el sistema sanitario costarricense en la década de 1990 se redujo la tasa de ausentismo en las instituciones públicas del sistema de salud, ya que este era uno de los objetivos de la reforma.

Esa reforma dio a los directores y gerentes mayor responsabilidad, autoridad y autonomía en áreas tales como el control del presupuesto y de los recursos humanos y administrativos. Además, se aplicó una nueva política de licencia por enfermedad según la cual no se asignaba un suplente para realizar las labores del trabajador ausente, con el propósito de reducir los costos y las tasas de ausentismo debidos a la presión que ejercerían los compañeros del que se ausentaba. Esta presión del colectivo de trabajo se vería reforzada por incentivos diseñados para lograr cambios en la cultura organizativa y por las nuevas normas de trabajo aplicadas en las instalaciones sanitarias.

$\mathrm{Al}$ analizar las tasas de ausentismo por enfermedad (el número de ausencias dividido por el número de trabajadores de la entidad) del personal sanitario de 29 hospitales públicos costarricenses entre 1995 y 2001, se encontró que estas aumentaron, especialmente en los hospitales grandes. Este aumento fue más ostensible a partir de 1997.

La tendencia creciente en las tasas de ausentismo se manifestó en todo el país, excepto en las regiones de Chorotega y Central Norte. La tasa de ausentismo en esta última fue, sin embargo, la más elevada del país, posiblemente debido a que abarca el área metropolitana, donde la demanda de atención médica es mayor y el personal sanitario puede estar trabajando bajo mayor presión. Además, esta es una de las regiones que más necesita consolidar los servicios de atención primaria.
En términos generales, es posible que las medidas aplicadas tuvieran un efecto negativo sobre las tasas de ausentismo por enfermedad, independientemente del tamaño del hospital. El mecanismo de presión del colectivo laboral podría haber funcionado si se hubiera aplicado el sistema de recompensa a los equipos de trabajo que tenían menos ausentismo, tal como estaba previsto. Por otro lado, los nuevos contratos de trabajo reforzaron el control y las sanciones a un nivel colectivo, pero no a nivel individual. La combinación de estos dos factores puede explicar por qué el nuevo sistema contractual no logró reducir las tasas de ausentismo.

La sobrecarga de trabajo del sistema sanitario de Costa Rica debido a diversos factores - como el compromiso de brindar atención sanitaria a todos los ciudadanos, el aumento de la inmigración y la violencia y no haber consolidado suficientemente los servicios de atención primaria de salud- provoca largas listas de espera y un aumento desmedido de la carga laboral de los trabajadores de los hospitales costarricenses. Esto puede haber influido en el aumento de la tasa de ausentismo por enfermedad en este sector.

Los directivos de los hospitales pequeños pueden haber estado bajo una mayor presión para reducir el ausentismo entre sus empleados y así poder cumplir con los objetivos establecidos en sus contratos, por ejemplo, reducir las listas de espera.

A pesar de este revés, se debe continuar diseñando y aplicando políticas dirigidas a reducir la tasa de ausentismo por enfermedad en las instituciones sanitarias. (García-Prado A, Chawla M. The impact of hospital management reforms on absenteeism in Costa Rica. Health Policy Plan. 2006;21(2): 91-100.)

\section{Uso de la reacción en cadena de la polimerasa para identificar aislamientos de Streptococcus pneumoniae resistentes a la penicilina}

La infección por Streptococcus pneumoniae es la más frecuente de las adquiridas en la comunidad y está asociada con alrededor de 3-5 millones de muertes al año en el mundo. La resistencia de este microorganismo a la penicilina ha aumentado mucho en los últimos años y se ha encontrado hasta en 78\% de los aislamientos en algunos países. La resistencia a antimicrobianos betalactámicos se debe 
exclusivamente a alteraciones en los genes bacterianos que codifican la proteína de unión a la penicilina (PUP) — el blanco natural de estos antibióticos-, de manera que al reducir su afinidad de unión la hace resistente a estos productos.

En este artículo se demuestra la aplicabilidad clínica de la reacción en cadena de la polimerasa (RCP) para detectar tempranamente la resistencia de $S$. pneumoniae a los antibióticos. Para ello se analizaron 153 aislamientos clínicos de esta bacteria aportados por varios hospitales del estado de Porto Alegre, Brasil.

A las muestras se les midió la concentración mínima inhibidora (CMI) de penicilina mediante la prueba de dilución en agar Mueller-Hinton con 5\% de sangre de carnero desfibrinada. Se consideraron susceptibles las cepas con una $\mathrm{CMI} \leq 0,06 \mu \mathrm{g} / \mathrm{mL}$, con resistencia intermedia cuando la CMI estaba entre 0,12 y $1,0 \mu \mathrm{g} / \mathrm{mL}$ y con alta resistencia cuando la $\mathrm{CMI} \geq 2,0 \mu \mathrm{g} / \mathrm{mL}$. Como control se empleó la cepa de S. pneumoniae ATCC 49619. Simultáneamente se realizó un análisis por RCP para detectar el gen lyt $A$ en la cepa aislada y se buscaron amplicones de tallas determinadas $1 \mathrm{a}, 2 \mathrm{~b}$ y $2 \mathrm{x}$ mediante cebadores específicos para los genes de la PUP.

Los resultados demostraron que la resistencia de S. pneumoniae a la penicilina en el sur de Brasil ha aumentado, aunque aún es menor que la observada en otros países. La tasa de cepas resistentes a la penicilina en Porto Alegre fue de 22,8\% (16,3\% con resistencia intermedia y $6,5 \%$ con resistencia alta). Una proporción estadísticamente significativa de las muestras susceptibles a la penicilina no tenían amplicones $(P=0,05), 84 \%$ de las muestras con resistencia intermedia tenían solo uno (por lo general el 2x) y las cepas altamente resistentes tenían los tres amplicones investigados.

La presencia de amplicones $2 x$ de la PUP en la mayoría de las cepas de $S$. pneumoniae con resistencia intermedia a la penicilina indica que estos pueden servir de marcadores de poca resistencia. Sin embargo, no se logró diferenciar las muestras con resistencia intermedia a la penicilina de las que tenían una elevada resistencia mediante la presencia o ausencia de amplicones $2 x$ del gen de la PUP, aunque la presencia simultánea de dos o tres amplicones diferentes se asoció significativamente con la expresión de una alta resistencia.

El diagnóstico molecular de la resistencia a la penicilina se dificulta debido a la asociación de múltiples PUP con el desarrollo de la resistencia. Sin embargo, este estudio demostró que mediante la RCP se pueden detectar tempranamente las cepas de S. pneumoniae con resistencia a antimicrobianos. Esta técnica es rápida y fácil de realizar en laboratorios habilitados para ello. Es necesario diseñar nuevos estudios que permitan determinar cuál de los PUP puede servir mejor de blanco en la RCP, de manera que permita detectar las cepas de neumococos resistentes a antibióticos betalactámicos. (Walker Zettler $\mathrm{E}$, et al. Determination of penicillin resistance in Streptococcus pneumoniae isolates from southern Brazil by PCR. Int J Infect Dis. 2006;10(2):110-5.)

\section{Infección natural del mosquito Lutzomyia neivai con Leishmania spp en Argentina}

La leishmaniasis es una enfermedad causada por parásitos del género Leishmania y transmitida en América por la picadura de mosquitos del género Lutzomyia (Diptera: Psychodidae: Phlebotominae). En el norte de Argentina se han detectado casos y epidemias de leishmaniasis cutánea americana (LCA) desde 1916. Entre 1991 y 1997 se han documentado 203 casos nuevos de esta enfermedad en la provincia argentina de Tucumán.

La especie Lutzomyia neivai se considera el principal vector de la LCA en Argentina; sin embargo, aún no se sabe si este mosquito se infecta de manera natural con el parásito. Conocer la tasa de infección natural de este vector e identificar las especies circulantes del parásito constituyen elementos de gran importancia para diseñar las medidas de vigilancia vectorial y epidemiológica.

El objetivo de este trabajo fue detectar la infección natural del mosquito vector con especies de leishmania en un área con LCA endémica del norte de Argentina y determinar el subgénero del parásito mediante técnicas de biología molecular. Además, se buscó confirmar que la especie $L u$. neivai puede transmitir la enfermedad en esta área, como se desprende de su distribución y abundancia estacional coincidente con el patrón epidemiológico de la LCA en esta zona.

Se recolectaron mosquitos en seis localidades de las provincias argentinas de Tucumán (cinco localidades) y Salta (una localidad), ambas en la zona noroccidental del país, entre noviembre de 1999 y enero de 2003. Después de la identificación morfológica, el ADN de 410 hembras de Lu. neivai (310 de Tucumán y 100 de Salta) se extrajo y se amplificó mediante la reacción en cadena de la polimerasa (RCP) con cebadores específicos de Leishmania spp, y se determinaron los subgéneros L. (Viannia) y L. (Leishmania) mediante técnicas de hibridación de ADN con sondas obtenidas de cepas de L. (V.) braziliensis y L. (L.) amazonensis.

De los 2749 insectos recolectados en Tucumán, 96,5\% pertenecían a la especie $L u$. neivai, 3,2\% a Lu. migonei y 0,3\% a Lu. shannoni. En Salta, la especie predominante fue también $L u$. neivai (94\%). 